Nouveaux visages de l'anglais de spécialité : objectifs, domaines, approches et outils de demain

\title{
From informal resource usage to incidental language acquisition: language uptake from online television viewing in English
}

Meryl Kusyk and Geoffrey Sockett

\section{CpenEdition}

\section{Journals}

Electronic version

URL: http://journals.openedition.org/asp/3104

DOI: 10.4000/asp.3104

ISSN: 2108-6354

\section{Publisher}

Groupe d'étude et de recherche en anglais de spécialité

Printed version

Date of publication: 15 November 2012

Number of pages: $45-65$

ISSN: 1246-8185

\section{Electronic reference}

Meryl Kusyk and Geoffrey Sockett, « From informal resource usage to incidental language acquisition: language uptake from online television viewing in English », ASp [Online], 62 | 2012, Online since 07 October 2014, connection on 02 November 2020. URL : http://journals.openedition.org/asp/3104 ; DOI : https://doi.org/10.4000/asp.3104

This text was automatically generated on 2 November 2020 .

Tous droits réservés 


\title{
From informal resource usage to incidental language acquisition: language uptake from online television viewing in English
}

\author{
Meryl Kusyk and Geoffrey Sockett
}

\section{Introduction}

1 Research into the Online Informal Learning of English (OILE) involves the study of a range of Internet-based communicative leisure activities through which learners are exposed to media content and interact with others in English. Several recent studies have sought to identify the breadth of activities involved, quantify the degree of exposure to the target language and characterize the structures to which learners are most frequently exposed. These activities include online viewing of original version television series, social networking in English and listening to English-language music on demand. This research is situated within the theoretical framework of Complex Dynamic Systems (Larsen-Freeman \& Cameron 2008), which sees exposure to a language and the learning of that language as involving a vast number of interacting variables in both the psycholinguistic and sociolinguistic spheres. This perspective also sees language as construction based (Goldberg 1995), and is compatible with associative/cognitive views of language learning (Ellis 2007).

2 Since OILE takes place in private and is not part of any structured language learning program, it presents considerable methodological challenges for the researcher more used to working in a classroom context. In order to obtain data, much research in this field focuses on university students who attend non-specialist English classes as part of their degree courses. English specialists are not a focus of these studies, since their relationship with the target language, with its focus on literature, civilization and linguistics, is quite unlike that of the majority of English users (Kail et al. 2009). 
3 The choice of non-specialists is justified by previous studies (such as Toffoli \& Sockett 2010) which suggest that more than half of these learners are involved in OILE activities on a regular basis. It is also significant that the most frequently occurring chunks of language to which informal learners are exposed in online television viewing (Sockett 2011), such as "what do you think" or "I want you to" are examples of volitional language common in expressing opinions or giving preferences. The CEFRL situates these at the B1 level, a level of proficiency frequently reported by respondents in these studies. ${ }^{1}$

4 The difficulty of defining informal learning as a series of activities carried out in an informal context is that the extent to which items are actually learned through exposure can prove difficult to demonstrate. In defining OILE as emerging from a communicative intention, Toffoli and Sockett (2010) suggest that acquisition in this context is incidental and as such, learners may not even be aware that learning is taking place, a position supported by Stevens and Shield (2010).

In the literature, researchers such as Skehan (1998) have sought to distance themselves from simple input hypothesis perspectives by stressing the importance of attention as a necessary step towards noticing, which in turn can lead to acquisition. Hulstijn's (2003) definition of incidental acquisition as learning without the intention to learn, while paying attention to another aspect of the stimulus, is useful in that it emphasizes the complexity inherent in the notion of attention. In informal learning, the learners' attention to the input material is clear, since all of the activities are chosen by them as leisure activities. The question here is whether or not attention to meaning, since we have defined informal learning as communication-driven, can to some extent lead to acquisition in the same way as attention to form can in the classroom.

On the other end of the learning-acquisition spectrum, Allwright (1984) and Ellis (1995) have used the term "uptake" to describe what learners identify as having learned at the end of or during a class. Slimani $(1987,1992)$ adds to this initial definition the items that simply attract learners' attention during instruction. This definition of uptake would therefore be considered a subsequent process in the language learning continuum, succeeding the initial input (the language data made available to the learner) and the secondary intake (the processing of these data).

7 When used to describe learning in formal environment, uptake therefore emphasizes the feedback given by learners about what they've learned or noticed. This concept, which has emerged from classroom-based research, may be usefully expanded in the context of the present study to include the learning of the meaning of structures, even when the learning processes are not available to introspection. It is therefore important to note that the term "uptake", as it is used in this article, refers more to the general nature of comprehension, and not to the technical, feedback-dependent definition proposed by Allwright, Ellis and Slimani.

8 Use of the terms "learning" and "uptake" also leads to a debate in the literature about the degree to which learners engage in informal activities with the intention of learning (Sockett 2011). Examples from the work of Develotte and Dervin (2011) highlight the fact that informal practices range from the intentional-learning focused, "I practice my Swedish language writing every third of my tweets in Swedish", to a simple by-product of a communicative intention, "I've practiced a language, yes, I've all my foreign friends on Facebook and they often post things in their respective languages, some of which I speak". While these examples tell us much about the 
ambiguity of the term "practice" in this context, they are also an indication that intentionality in informal learning may be a fruitful area for further research.

The issues addressed in this article are therefore methodological and empirical. In what ways can the effect of informal learning on incidental acquisition be measured and what do these measurements tell us about how English is learned in an informal online context?

10 Kuppens' 2010 article on informal vocabulary acquisition among Dutch children shows how this type of research can be carried out in a more classroom-based environment, where input materials are selected by the researcher, while Webb and Rogers (2009) have also studied the vocabulary demands of television viewing without specifying the potential audience. Each of these authors points out that the field is rarely studied and that empirical data on $\mathrm{L} 2$ television viewing is difficult to find in the literature.

11 The particular focus of this article is uptake of constructions heard during online viewing of American television series in their original version and follows on from a previous study (Sockett 2011) in which the most frequent groups of four words were identified from a corpus of some 500,000 words of dialogue from American series frequently viewed by learners.

The research hypothesis is that frequent viewing of television series in English has a positive effect on the acquisition of the meaning of the most frequently occurring chunks of language in those series.

\section{Methodology}

The 45 students that participated in this study are currently enrolled in information technology degree programs. The majority (34) are in a Licence professionnelle (vocational undergraduate degree program) at the Robert Schuman University Institute of Technology (IUT), while the remaining 11 are students at the Superior National School for Industrial and Business Computing (ENSIIE). Both campuses are located in Illkirch, just south of Strasbourg, France. Six students are female and six are foreign (three Romanians, three Chinese). The elicitation phases of the study took place during the students' weekly English classes. These classes are designed for the non-specialist learner (that is, these students are not specialists in English language and literature) and are a required component of their degree programs. Class content is organized according to the wishes and needs of the students (based on input given at the beginning of the semester) as well as the objectives defined by the institution (improving students' oral expression, preparing them for interactions and work in the professional sphere and exposing them to different Anglophone cultures).

14 A self-evaluation was completed at the beginning of the year, revealing a range of English language skills, the respondents situating themselves in the following levels of the CEFRL: A2: 1 student, B1: 22 students, B2: 12 students, C1: 9 students, C2: 1 student.

As the majority of students fall into the B-level category of "independent users", they are in theory able to understand "the main point of many radio or TV programs on current affairs or topics of personal or professional interest when the delivery is relatively slow and clear" (B1 level) and/or "most TV news and current affairs programs [and] the majority of films in standard dialect" (B2 level). 

test. The survey aimed at identifying their viewing habits and included questions on
how often they watch American television series, their favorite series and questions
relating to the use of subtitles in English or French (see appendix 1). colleagues' suggestions and critiques helped ensure that its scientific content was appropriate for the study at hand. Then, a pre-test group ${ }^{2}$ completed the survey in order to give feedback and identify potential areas of confusion. Subsequent changes were then made. For example, question 5 of the viewing habits survey was clarified so that it would refer particularly to how much dialogue students understand vis-à-vis their most common viewing mode. The original question was of a more general nature, thus prompting students to specify that their level of comprehension changes depending on viewing format.

The vocabulary test involved the students listening to a number of different phrases ( 42 in total; see appendix 2) and rating, according to a vocabulary knowledge scale, their level of understanding for each specific phrase (see appendix 3). The list of phrases was taken from Sockett's (2011) 50 most commonly occurring word clusters in popular American television shows. Eight of the clusters were removed due to overlapping or irrelevance. ${ }^{3}$ As the clusters were not complete sentences themselves, and since the students did not know that they were only being tested on certain isolated word chunks, these were placed into short, simple phrases in order to provide a coherent whole that the students could rate. For example, "How do you know where I live?" contains the group of words to be tested in bold, while the end of the phrase provides a simple context, without which the sentence could appear incomplete and confusing to the research subjects. It is important to note that this is a study measuring oral comprehension, the aim of which is to capture data on how much students understand while they participate in the informal activity of watching American television for leisure. Therefore, the words clusters were never available to the students in isolated, written form and were only presented orally, contextualized in an entire sentence, via an audio file.

19 The vocabulary test was validated in the same manner as the viewing habits survey. During this pre-test phase, it was agreed upon by both students and researchers that the amount of time allotted to rate each phrase should be 30 seconds.

\section{The Vocabulary Knowledge Scale}

The Vocabulary Knowledge Scale (VKS) mentioned above is an adapted version of a model created by Paribakht and Wesche (1993) as part of a study on written comprehension. Their study specifically focused on the acquisition of grammatical knowledge and vocabulary as well as the development of a methodology and different tools that could be used to conduct research on these aspects in the classroom.

Their scale consisted of five points among which research subjects chose to evaluate their understanding of a given word:

1. I have never seen this word.

2. I have seen this word before, but I don't know what it means.

3. I have seen this word before, and I think it means: (synonym or translation)

ASp, 62 | 2012 
4. I know this word. It means: (synonym or translation)

5. I can use this word in a sentence:

The VKS is a useful tool for the current study in a number of ways. Firstly, it allows both a self-evaluation (the student rates the item from 1 to 5) and instructor verification (numbers 3,4 , and 5 must be provided with a synonym, translation, or an example sentence, which are then verified to ensure that the student correctly understands the word [or not]). Secondly, the VKS gives an approximate idea of "where" a given word is situated on a student's individual vocabulary spectrum, since a scale is used rather than open questions inviting the learner to describe their degree of knowledge of the item. Finally, as the scale is numbered, it allows for straightforward quantification of results.

There are, however, limits to this evaluative tool. While one of its positive aspects is that it gives an approximation of the degree of acquisition of a range of terms, it is important to keep in mind that this indeed is only an estimation, and both learner selfevaluation and rater assessment can be subjective. Since the test is a snapshot of vocabulary knowledge at a given time, parameters such as degree of activation of certain terms in long-term memory, which varies according to context, may affect results. Indeed, if the VKS were to be used as a diachronic tool, it is likely that repeated testing on the same terms would also have an impact on acquisition.

In addition, although the scale is presented in a linear progression, it is not entirely so. According to the progression of the scale, level 5 would demonstrate the full acquisition of a word and the ability to use it in a sentence. However, the order in which a learner acquires a word may not advance in the linear manner that the scale suggests. For example, being able to use a word in a sentence is something one could do without necessarily knowing exactly what the word means - in this case, level 5 could be reached before levels 3 or 4 .

\section{The Adapted VKS}

Because of the limits discovered regarding the original scale, the following changes were introduced to make it more effective in the context of this study:

Removal of level 5, because the cluster would already be presented in sentence form, therefore it would be redundant and unnecessary to ask the students to use the cluster in another sentence.

Modification of the wording from "seen" to "heard", as oral and not written comprehension is targeted.

"Phrase" is used instead of "word" as clusters (embedded within a sentence) and not just single words are the focus of this study. "Phrase" was thought to be more accessible to learners than "chunk", "structure" or "cluster".

The term "or a similar structure" was added in order to allow for more flexibility in students' recognition of the phrase. That is, if a student had already heard the sentence "I have to go to the store" but during the test he or she hears "I have to go to the hospital", they can say that they "know" the phrase because the structure is the same.

These modifications combine to form an adapted Vocabulary Knowledge Scale (changes in bold): 
1. I don't remember having heard this phrase (or a similar structure) before.

2. I have heard this phrase (or a similar structure) before, but I don't know what it means.

3. I think I know what this phrase means. I think it means: (translation).

4. I am sure I know what this phrase means. It means: (translation).

31 The 42 phrases heard during the vocabulary test were pre-recorded by an American colleague. Recording allows for greater consistency between the different groups, and it was considered important to use an American native speaker as the majority of the series watched feature general American accents. The students heard each phrase only once, in an attempt to simulate a "watching for leisure" context, in which it is not likely that phrases would be replayed numerous times in order to dissect their meaning.

The vocabulary test was completed during a normal class period. The students first filled out the viewing habits survey, followed by the adapted VKS test. The process for the latter was as follows:

1- The students listened to one audio file, once (one audio file $=$ one of the 42 test phrases).

34 2- The students had 30 seconds to rate their level of comprehension according to the adapted VKS and translate the phrase, if levels 3 or 4 were chosen.

\section{Results}

\section{Viewing habits survey}

The viewing habits survey was nominative and contained eleven questions in total. The first question dealt with how often students watch series in English. Indeed, as this study's central research question refers to the frequency/ acquisition relationship, it was imperative to know how often students engage in informal viewing. 
Figure 1. Viewing frequency

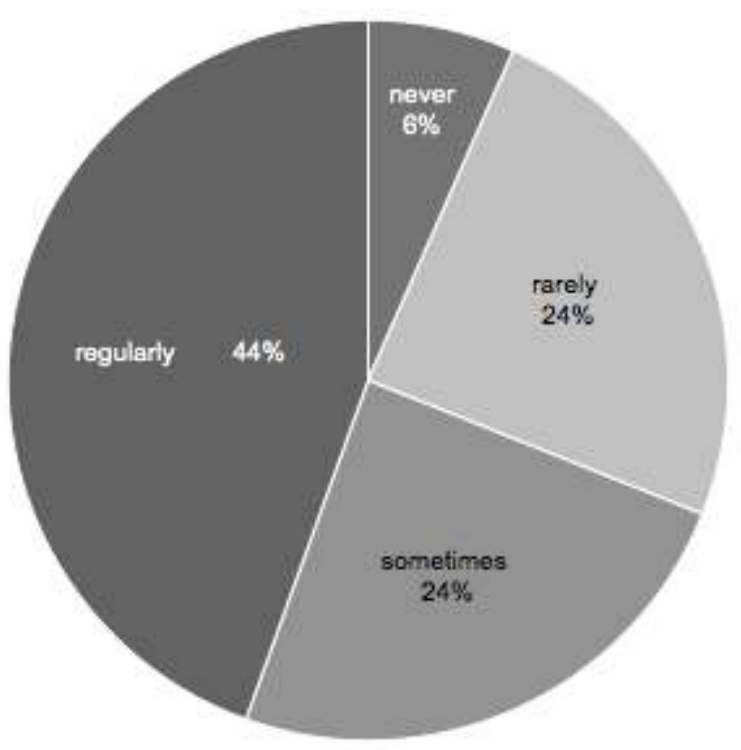

As Figure 1 shows, nearly half of all students claim to watch series in English regularly, in this case, more than once per week. Only six percent never watch, and one quarter each watch sometimes (between once per month and once per week) or rarely (less than once per month). Comparing these results to a recent study done with humanities students (Sockett forthcoming), we observe a similar breakdown in viewing habits: $33 \%$ watch weekly, $23 \%$ watch sometimes, $23 \%$ watch rarely and $17 \%$ never watch. Each student noted the three series that they most often watch, which allows the following list of most frequently viewed series to be drawn up:

- Walking Dead

- How I Met Your Mother

- Big Bang Theory

- Fringe

- House

- Breaking Bad

- South Park

- The Mentalist

- Castle

- Dexter

The main genres appear to be science fiction (Fringe), horror (Walking Dead), dramas (House, Breaking Bad), comedies (How I Met Your Mother, Big Bang Theory) and period dramas (Game of Thrones, Spartacus). 
Figure 2. Viewing modes

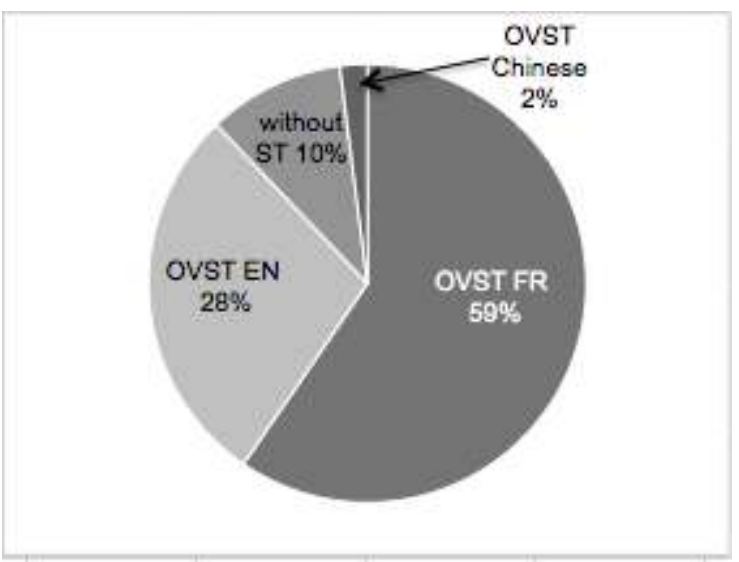

Concerning the different modes of viewing, Figure 2 shows that the largest percentage of students watch in original version with French subtitles (OVST FR) followed by those who watch in original version with English subtitles (OVSR EN). Minority modes of viewing were without subtitles (without ST) and in original version with Chinese subtitles (OVST Chinese).

Figure 3. Access modes

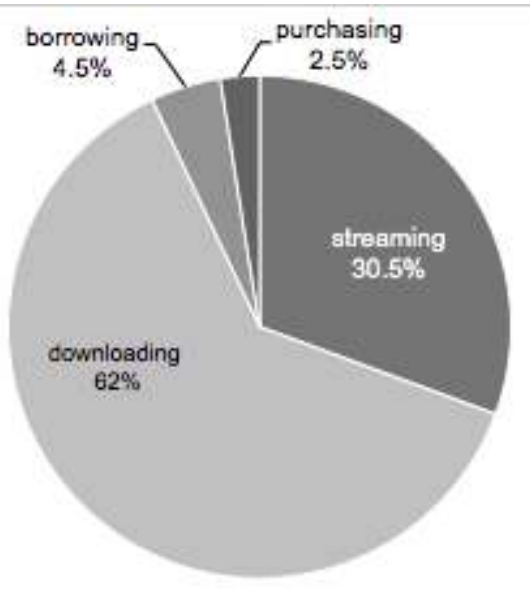

Students were then asked a follow-up question: How (in which viewing mode) would you like to watch, if you had the choice? Their answers revealed that $60 \%$ already watch in the mode that they prefer. of the $40 \%$ who do not, close to half (47\%) currently watch with French subtitles though would like to watch with English subtitles or without subtitles at all.

One of the survey questions asked students how they acquire the episodes they watch (Figure 3). 62\% download, 30.5\% watch via streaming, and a small minority borrow from friends and family (4.5\%) or purchase the series (2.5\%).

Also linked to the mode of procurement is the recent closure (January 19th 2012) of megavideo.com, a file-hosting website that allowed its users to store and view data via streaming. It was therefore quite common to stream series and films via this site. As one could expect, since the majority (62\%) of research subjects download, the majority (77\%) also feel unaffected by the shutting down of megavideo.com. In addition, only $24 \%$ 
of students think that its general consequences (the effects on the general public) are serious - the rest think that it is but a short-term inconvenience and that other filehosting websites will soon appear. Interestingly, comparison with Sockett's forthcoming study involving humanities students shows that these students are affected by the closure of megavideo.com: $57 \%$ confirm that their viewing habits have since changed. This difference could be due to the fact that the research subjects featured in the current study are information technology students and thus are well equipped and adapted to finding what they seek on the Internet. It may therefore be a question of Internet navigation skills, or perhaps the rate at which the humanities students stream rather than download series.

As this study is concerned with whether or not students acquire certain constructions while watching television, it was important to ask students about their own opinions regarding the potential learning that takes place during informal viewing.

Figure 4. Percentage of students who have the impression that they learn expressions

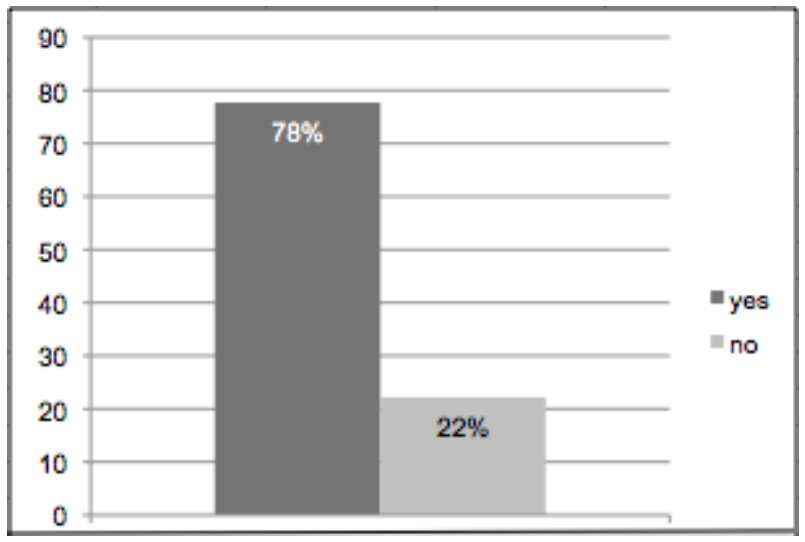

44 As Figure 4 illustrates, the large majority of students who watch television series in English feel that they learn expressions or vocabulary. This impression is especially prevalent among those that watch regularly (Figure 5).

Figure 5. Percentage of regular watchers who have the impression that they learn expressions

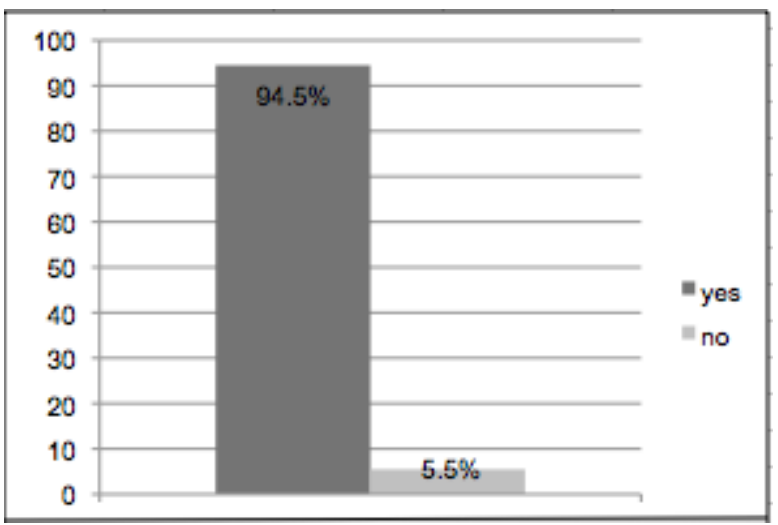

The conclusion of the viewing habits survey focused on general oral comprehension and reasons for watching in English. Concerning the former, students were asked, "According to the mode in which you most often watch, how much of the dialogue in English do you feel you understand?". This question tried to isolate the students' 
impressions of their oral comprehension ("the dialogue in English"), but it is clear that the different viewing modes (with or without subtitles, English or French subtitles) as well as the specific series watched obviously affect and bias this impression.

Figure 6. Regular watchers: percentage of comprehension of English dialogue

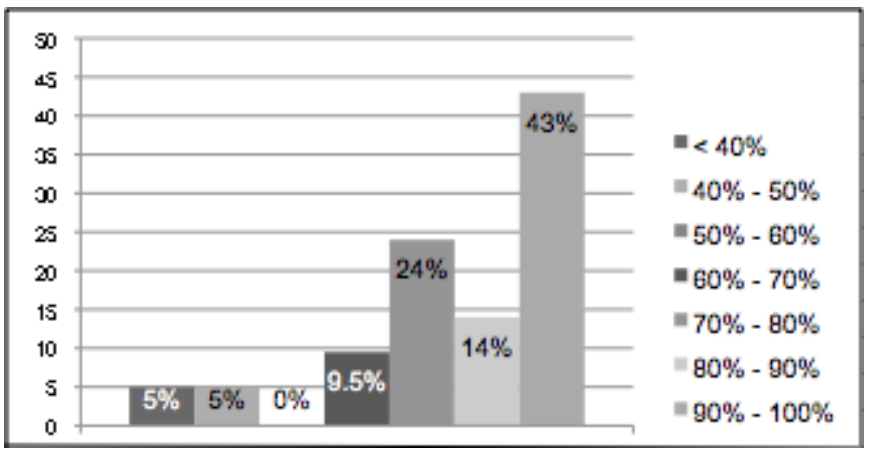

Taking into consideration the natural limits of this question, it is nevertheless interesting to point out the stark difference between regular watchers (Figure 6) and non-regular watchers (Figure 7). $43 \%$ of regular watchers feel that they understand between $90 \%$ and $100 \%$ of the dialogues in English, whereas only $13.5 \%$ of non-regular watchers feel this way. $81 \%$ of regular watchers claim to be able to understand $70 \%$ or more of the dialogues, while only $49.5 \%$ of non-regular watchers make the same claim. Though these percentages must be interpreted with reservation due to the inherent limits of the question, they do point to quite different impressions of dialogue comprehension between regular and non-regular watchers.

Figure 7. Non-regular watchers: percentage of comprehension of English dialogue

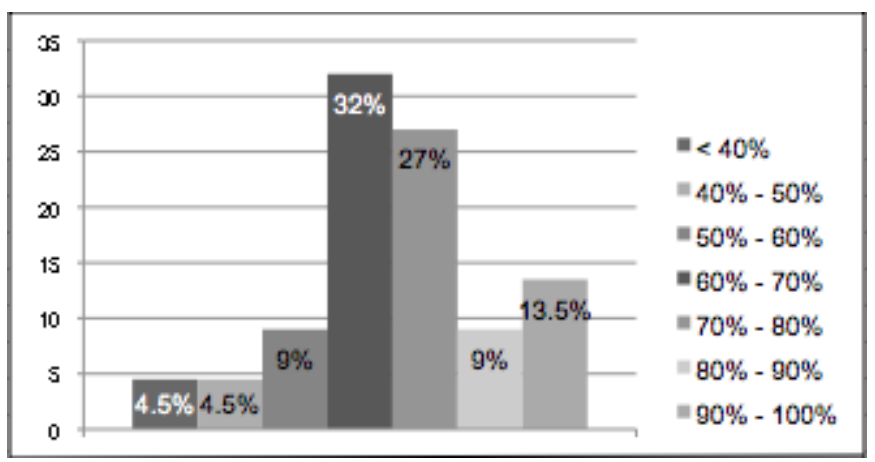

47 Finally, students were asked to note the various reasons as to why they choose to watch series in English. (They were allowed to list as many as they wished.) 
Figure 8. Reasons for watching series in English

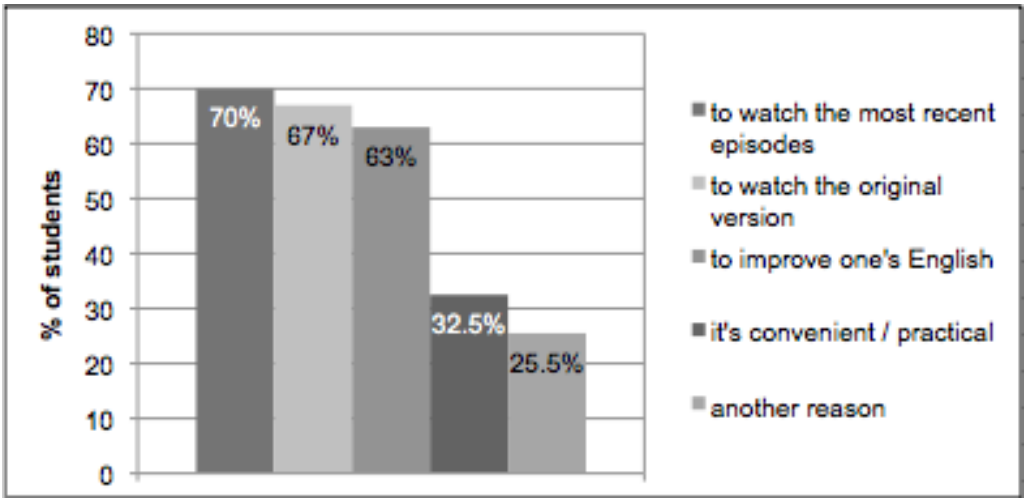

According to Figure 8, the majority of students selected more than one reason. The three most common were being able to watch the most recent episodes (70\%), authenticity (67\%) and the possibility of improving one's English (63\%). Further research is needed to determine which active measures, if any, students undertake to improve their English while watching series (stopping, replaying scenes, noting and looking up unknown vocabulary, etc.). As a relatively new frontier in incidental language acquisition, watching television series and films online offers a wide array of learning possibilities. It is not currently known to what extent learners take advantage of these affordances, or rather if they are content to watch as a leisure activity.

In the following section, the quantitative results of this study are explained and discussed.

\section{VKS test}

The results of the VKS test were organized according to level (1-4), and translations were verified. $0.49 \%$ of students chose level 1, "I don't remember having heard this phrase (or a similar structure) before" for one or more of the phrases. $0.91 \%$ chose level 2, "I have heard this phrase (or a similar structure) before, but I don't know what it means" for one or more of the phrases. 6.9\% chose level 3, "I think I know what this phrase means. I think it means: (translation)" and $91.7 \%$ chose level 4 , "I am sure I know what this phrase means. It means: (translation)". Table 1 offers an example of the organization of this breakdown.

Table 1. Results for VKS - Example table

\begin{tabular}{|c|c|c|c|c|c|c|c|c|c|c|c|c|c|}
\hline & L1 & $\begin{array}{c}\text { 1: which } \\
\text { phrases ? }\end{array}$ & L2 & $\begin{array}{c}\text { 2: which } \\
\text { phrases ? }\end{array}$ & L3 & $\begin{array}{c}\text { 3: which } \\
\text { phrases ? }\end{array}$ & $\begin{array}{c}\text { Number of level } \\
\text { 3 correct/ } \\
\text { incorrect (which } \\
\text { ones) }\end{array}$ & \multicolumn{3}{|c|}{$\begin{array}{c}\text { L4 } \\
\text { Number of level 4 } \\
\text { correct/ incorrect } \\
\text { (which ones) }\end{array}$} \\
\hline $\begin{array}{c}\text { Student } \\
1\end{array}$ & $\mathbf{0}$ & & $\mathbf{0}$ & & $\mathbf{7}$ & $\begin{array}{c}\# 5,13, \\
15,16, \\
34,38, \\
42\end{array}$ & 7 & 0 & & $\mathbf{3 5}$ & 33 & 2 & $\# 8,29$ \\
\hline $\begin{array}{c}\text { Student } \\
2\end{array}$ & $\mathbf{1}$ & $\# 15$ & $\mathbf{0}$ & & $\mathbf{0}$ & & $/$ & $/$ & & $\mathbf{4 1}$ & 39 & 2 & $\begin{array}{c}\# 21, \\
38\end{array}$ \\
\hline $\begin{array}{c}\text { Student } \\
3\end{array}$ & $\mathbf{0}$ & & $\mathbf{1}$ & $\# 17$ & $\mathbf{0}$ & & $/$ & $/$ & & $\mathbf{4 1}$ & 41 & 0 & \\
\hline
\end{tabular}

51 According to this example table, student 1 did not choose level 1 nor 2 to rate any of the phrases he/she heard. Student 1 selected level 3 seven times, for the phrases 5, 13, 
$15,16,34,38$ and 42 . All of the proposed translations for these phrases were verified as correct. Finally, the rest of the phrases were attributed level 4 . Thirty-three of these translations were verified as correct, while two were not (phrases 8 and 29). Since the majority of students rated the phrases they heard as level 4 , it was not necessary to note "which phrases" for this category as was done for the other levels (only the phrases that were incorrectly translated were noted). Indeed, the point of noting such exception phrases (for the levels 1,2 and 3) was to be able to draw possible conclusions about particular phrases that posed a problem for students. Such exceptions will be discussed below.

For the purpose of this study, the quantitative results focus specifically on level 4 data and translations. Level 4 is distinguished from the others because it is the level at which students claim to be sure of their knowledge of the phrase, whereas the other levels leave room for doubt or uncertainty. The aim of this study is to measure comprehension, and to try to determine if this comprehension is due to viewingrelated acquisition. It is therefore necessary to assess what has been verifiably learned, and not what remains unsure.

The additional variable of frequency is taken into account in the quantification of results. Indeed, in order to know if viewing affects acquisition, this action must be isolated in terms of how often it is done; that is, if it is regular or not. Therefore, the regular watchers (those who watch more than once per week) have been distinguished from non-regular watchers.

Table 2

\begin{tabular}{|l|c|c|c|c|}
\hline & L4 & \multicolumn{4}{|c|}{ Number of level 4 correct/incorrect (which ones) } \\
\hline Regular watcher A & 42 & 40 & 2 & $\# 21,38$ \\
\hline Regular watcher B & 42 & 42 & 0 & \\
\hline Regular watcher C & 36 & 36 & 0 & \\
\hline Regular watcher D & 35 & 33 & 2 & $\# 8,29$ \\
\hline
\end{tabular}

In order to determine most clearly if viewing series in English has an effect on oral comprehension, the averages of the correctly translated level 4 phrases (see the grey column of Table 2) were compared between regular and non-regular watchers. This column reflects how many times students chose level 4 ("I am sure I know the meaning of this phrase") to classify their understanding of a given phrase and the verification of this knowledge as being correct (verification of the students' translations). For example, according to Table 2 regular watcher A chose level 4 for all of the phrases he/ she heard. Two translations were deemed incorrect (phrases 21 and 38), therefore this student is left with a "score" of 40/42 (40 correctly translated level 4 phrases).

The students' scores yielded the following averages: 
56 $38.8 / 42$ $34.58 / 42$. As 2.99 is greater than this value, it can be concluded with a degree of certaint 99.5\% that the difference between the two averages is due to watching series in English. In other words, this difference would only occur by chance once out of 200 times.

60 Although this calculation provides a high degree of certainty, another t-test was done in an attempt to reduce some of the randomness of the former. More specifically, the first calculation pits regular watchers against non-regular watchers. Among these nonregular watchers is a wide array of viewing frequency (from once per week to never) and oral comprehension skills (self-evaluated levels ranging from A2 to C1). Indeed, the independence of the variables in this study is difficult to establish since the learners' level in English may be both a cause and a consequence of regular online television viewing.

61 A subset was therefore identified for closer analysis. The twelve students that identified themselves as B2 have varying, but evenly distributed, viewing frequencies: six watch more than once per week while the other six watch less than once per week. (The C1 and B1 students' viewing frequencies are not evenly distributed, thereby making them less suitable candidates for analysis.) The score averages of the two subgroups were thus analyzed:

62 - Regular watchers correctly translated level 4 phrases with an average score of $40.3 / 42$.

63 - Non-regular watchers correctly translated level 4 phrases with an average score of $36.5 / 42$.

64 A t-test yielded a coefficient of 2.84. The coefficient critical value for the 0.05 level is 2.23. As the t-test coefficient is greater than this value, it can be said with a degree of certainty of $95 \%$ that the difference between the two averages is due to watching series in English. This difference would occur by chance once out of 20 times.

These quantitative analyses demonstrate that language development is taking place as learners watch series in English. It was shown that with both heterogeneous and homogeneous group levels, frequent viewing was the key difference in comprehension scores.

66 The final research question of this study focuses on whether certain structures appear to be more easily acquired than others. More specifically, observations were made regarding the distribution of students' scores on the vocabulary test in an attempt to identify key phrases or structures that posed a problem. Cluster frequency (how often a cluster occurs in a series, according to the HHOLD corpus ${ }^{4}$ [Sockett 2011]) was examined, as frequency is a major theme in Ellis' (2007) CREED model and elsewhere in 
the theoretical models underpinning this study. Figure 9 shows a frequency distribution of regular watchers' level 4 phrases that were marked wrong more than once during the verification phase.

Figure 9. Vocabulary test

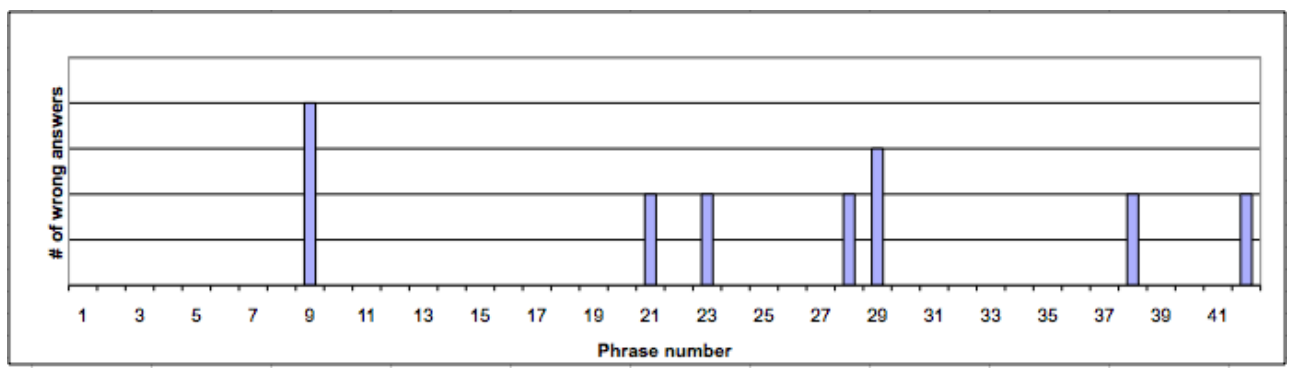

67 According to the figure above, the following phrases posed the biggest problem for students:

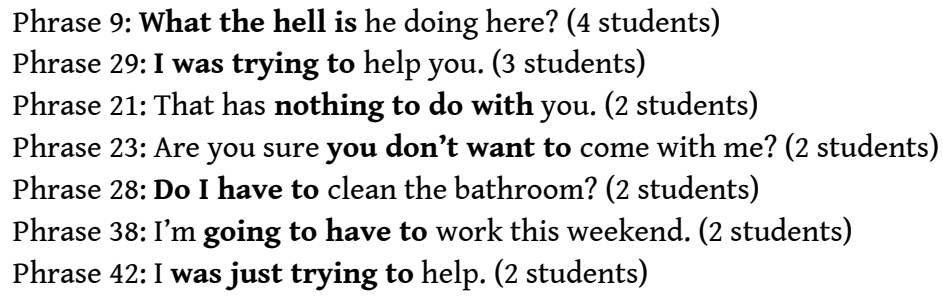

It should be noted that the order of the phrases reflects their series frequency (how often they appear in the series). Phrase 8 thus appears more often than phrase 15 , and so forth. Figure 9 shows that all except one of the "problem" phrases occur in the second half of the HHOLD corpus. In other words, the majority of the phrases that were marked wrong more than once are present in the lower-frequency half of the corpus. It seems, therefore, that there would be a positive relationship between phrase acquisition and cluster frequency: the more a phrase occurs (is heard), the more likely it is to be acquired. Saliency also seems to be a factor, since the exception to this tendency (Phrase 9: What the hell is he doing here?), is an example of an emphatic structure which does not primarily give information about the narrative of the series.

\section{Discussion}

Certain responses to the viewing habits survey warrant reflection and discussion. Firstly, the question about viewing mode brings up an interesting point concerning students' presumed comprehension skills. 11 students (22\% of research subjects) selfevaluated themselves at a C level (10 C1 and $1 \mathrm{C} 2)$, which implies that they can understand television shows and films without too much effort and/or have no difficulty in oral comprehension, respectively. And yet, only $10 \%$ indicated that they watch without subtitles. Further investigation into the reasons for choosing a subtitled version of the series may yield insights into the way such visual aids enable the $12 \%$ of learners who should not need subtitles to focus more on meaning in the series they watch. 
Secondly, in reference to current viewing mode versus preferred viewing mode, it was revealed that $40 \%$ of students currently do not watch in their favored mode. These results thus beg the question: do they currently not watch in their preferred format because they are unable to obtain this format (a logistics issue) or because they are not able to understand without French subtitles (a language skills issue)? Since the majority of students download their series, one could suppose that they are indeed capable of obtaining whichever format they wish. File-sharing websites generally offer versions of series with informally contributed French subtitles and with the original closed-caption English subtitles. Therefore the reason why a considerable amount of them do not watch in their preferred viewing mode is probably linked to comprehension issues. The notion of preference therefore becomes one of an imagined future self (Dörnyei\& Ushioda 2009), in which learners subconsciously fix for themselves the goal of viewing without subtitles. This goal fixing is interesting in an informal context as it is more usually associated with formal learning and may tell us something about the way motivation works as a fixed attractor in these leisure activities.

71 Finally, regarding how much dialogue in English students feel they are able to understand, it was shown that regular watchers self-evaluate their oral comprehension skills at a higher percentage that non-regular watchers (43\% versus $13.5 \%$ for $90-100 \%$ comprehension; $81 \%$ versus $49.5 \%$ for $70 \%$ or more comprehension). As suggested above, these data prompt a "chicken and egg" question: do regular watchers understand more because they watch more (i.e., they learn thanks to watching) or do they already have strong language skills that allow them to understand (i.e., they can watch thanks to their preexisting skills)? It is probable, as in most complex models, that these factors influence each other and evolve through time, with an initial level of comprehension being necessary to break through into viewing in English. Subsequent gains in listening comprehension may then occur as a result of a range of factors surrounding regular viewing, such as familiarity of the situations, frequency of the items, focus on meaning and affective filter (Sockett \& Toffoli 2012).

\section{Study Limits and Perspectives}

72 This study attempted to measure the potential language acquisition that results from watching television series in English. Due to the informal and very individualized environment in which this acquisition is believed to occur, there are a certain number of inherent limits that need to be addressed. Firstly, it must be acknowledged that the evaluation phase (the vocabulary test) did not fully simulate learners' actual viewing experience. That is, they were presented with an audio file, which differs greatly from the original choice of medium. It is likely, therefore, that this presentation difference could have affected students' performance on the test. Secondly, the study is based on a corpus of the 50 most common word clusters heard in popular television series, though the responses to the viewing habits survey show that some of our research subjects watch series that are not included in this corpus. This too could have resulted in certain students being unfamiliar with some of the word clusters, although it is hypothesized that due to the variety of genres it includes, the HHOLD corpus is representative of language found in a wide range of American television series.

73 A challenge encountered during the methodology phase of this study was the creation of contextualized, whole phrases for the vocabulary test that would assess students' 
comprehension of the targeted word chunks, but that would not contain any superfluous, confusing language. For example, the cluster "do you want to" could have had various endings. We chose "come with me?" as it both contextualized the target word cluster and was simple in structure and word choice, thus allowing a strong possibility that students would understand the entire sentence. In this sense, we tried to make all non-cluster words as simple and direct as possible, so that comprehension would not be clouded by any non-target language.

In the same vein, during the verification phase it proved sometimes difficult to isolate students' demonstrated knowledge of the general sense of the phrase versus their demonstrated knowledge of the specific cluster. For example, "I was trying to help you" was translated by several students as "je voulais t'aider". The verb vouloir means to want, and not to try, however in French it may be more idiomatic to say "je voulais t'aider " rather than "j'essayais de t'aider". The overall meaning is basically the same, but the verbs differ. On the other hand, some students translated the above phrase as " $j$ 'étais en train d'essayer de t'aider", which is word for word the same phrase, however not at all idiomatic.

The results of the current study allow for different points of departure for further research in the domain of online informal learning of English (OILE). While the present study does not include any diachronic analysis, it would be interesting to examine students' incidental acquisition as it emerges over time, and more specifically measure this acquisition with more precise evaluation tools. In addition, this study brings up questions and issues concerning OILE and students' time spent on the Internet today. What are the finer, more detailed aspects of the relationship between exposure time and acquisition? Indeed, this study concentrated on the level 4 items identified by the learners and did not look in great detail at the level 2 and 3 items, which may be said to be in the process of being learned.

In terms of pedagogical applications, one might consider how Internet-based access to English may be used as a tool in the classroom and what its effects may be on the other four language skills of the CEFRL. Further research is needed to address these questions in order for OILE and its language acquisition capacities to be fully understood and used in the most fruitful way possible.

\section{Conclusion}

As work on the online informal learning of English develops from the analysis of a sociological phenomenon (informal access to media), to the measurement of the resulting language development, a number of initial hypotheses have been confirmed. User participation in OILE is widespread, and a vast and diverse gamut of activities is available to learners. Although it does not primarily involve a conscious choice to learn English, a range of motivations are at work which require further analysis, as does the evolution of these influences through time. The fact that language development has clearly been demonstrated, within the framework of a construction-based view of language, leads to a theoretical question about the nature of attention in language learning, since attention to meaning rather than form is prevalent in informal learning. Since constructions are being learned in this way, it is also likely that they would be visible in production activities. Further studies are now underway to determine the extent to which frequent online viewers reuse the chunks of language mentioned in 
this study in their writing activities. In the future, the effect of OILE on oral production, which is attested by some teachers (Toffoli \& Sockett 2012), should also be investigated empirically.

\section{BIBLIOGRAPHY}

Allwright, Richard. 1984. "Why don't learners learn what teachers teach?: The interaction hypothesis". In Singleton D. M. \& D. Little (eds.), Language Learning in Formal and Informal Contexts. Dublin: Irish Association for Applied Linguistics, 3-18.

Common European Framework of Reference for Languages (CEFRL). 2001. Language Policy Division. Council of Europe, Strasbourg. Cambridge: Cambridge University Press.

Develotte, Christine and Fred Dervin. 2011. "Médias sociaux et enseignement/apprentissage des langues : liens réels ou fantasmés ? Où en est-on ?". Colloque international EPAL, Grenoble. <http://vimeo.com/channels/218407>, retrieved September 2012.

Dörnyei, Zoltan and Ema Ushioda (eds.). 2009. Motivation, Language Identity, and the L2 Self. Bristol: Multilingual Matters.

Ellis, Nick. 2007. "The associative cognitive creed". In VanPatten B. \& J. Williams (eds.), Theories in Second Language Acquisition. Mahwah, NJ: Lawrence Erlbaum Associates.

Ellis, Rob. 1995. “Uptake as language awareness". Language Awareness 4, 147-160.

Goldberg, Adele. 1995. Constructions: A construction grammar approach to argument structure. Chicago: University of Chicago Press.

Hulstijn, Jan. 2003. "Incidental and intentional learning”. In Doughty C.J.\& M. H. Long (eds.), The Handbook of Second Language Acquisition. Oxford: Blackwell, 349-381.

Kail, Michèle, Michel Fayol and Maya Hickmann. 2009. Apprentissage des langues. Paris: CNRS Éditions.

Kuppens, An. 2010. "Incidental foreign language acquisition from media exposure". Learning, Media and Technology 35/1, 65-85.

Larsen-Freeman, Diane and Lynne Cameron. 2008. Complex Systems and Applied Linguistics. Cambridge: Cambridge University Press.

Paribakht, Taherehand Marjorie Wesche. 1993. "Reading comprehension and second language development in a comprehension-based ESL program". TESL Canada Journal 11/1, 9-29.

Skehan, Peter. 1998. A Cognitive Approach to Language Learning. Oxford: Oxford University Press.

Slimani, Assia. 1987. "The teaching-learning relationship: Learning opportunities and learning outcomes". Lancaster, UK: Lancaster University. Ph.D. dissertation.

Slimani, Assia. 1992. "Evaluation of classroom interaction". In Alderson J. C. \& A. Beretta (eds.), Evaluating Second Language Education. Cambridge: Cambridge University Press, 197-220. 
Sockett, Geoffrey. 2011. "From the cultural hegemony of English to online informal learning: Cluster frequency as an indicator of relevance in authentic documents". ASp 60, 5-20

Sockett, Geoffrey. 2012. "L'impact des activités informelles d'écoute en anglais sur les travaux écrits d'étudiants LANSAD, une analyse quantitative". Communication au colloque ACEDLE, Université de Nantes. Proceedings forthcoming.

Stevens, Anne and Lesley Shield (eds.). 2010. "Étude sur l'impact des technologies de l'information et de la communication (TIC) et des nouveaux médias sur l'apprentissage des langues". Commission Européenne. <http://eacea.ec.europa.eu/llp/studies/documents/ study_impact_ict_new_media_language_learning/final_report_fr.pdf $>$, retrieved September 2012.

Toffoli, Denyze and Geoffrey Sockett. 2010. "How non-specialist students of English practice informal learning using web 2.0 tools”. ASp 58, 125-144.

Toffoli, Denyze and Geoffrey Sockett. 2012. "University teachers' use of their students' Online Informal Learning of English". Paper presented at EuroCALL SIG: Teacher education and CMC. University of Bologna.

Webb, Stuart and Michael Rogers. 2009. "Vocabulary demands of television programs". Language Learning 59/2, 335-366.

\section{NOTES}

1. See page 34 of the CEFRL for a more detailed description of the B1 level.

2. The pre-test group was of the same demographic as the actual research subjects: information technology students in a Licence professionnelle degree program at the University of Strasbourg.

3. Overlapping chunks include "are you talking about" and "what are you talking". As these two chunks refer to the same phrase ("what are you talking about"), it is not necessary to include both. Chunks removed on grounds of relevance include "no no no no" and "son of a bitch". Sockett (2011) found that these structures were the only ones not to contain a verb, expressing emotion rather than describing events in the series and were not good candidates for a translation exercise. A number of expressions containing the term "the hell" inserted into another structure were also consolidated into a single item.

4. The HHOLD corpus contains the fifty most frequently occurring 4-grams in five American television shows: House, How I Met Your Mother, One Tree Hill, Lost and Desperate Housewives.

\section{ABSTRACTS}

Research into the online informal learning of English has established that this phenomenon is widespread amongst non-specialist learners of English in French universities, and has characterized the type and quantity of input learners are exposed to as they view originalversion television series via downloading or streaming. In this study, learners first responded to a survey in order to indicate the frequency with which they view such material. Then they took part in a test, using a vocabulary knowledge scale to indicate their familiarity with sentences, 
presented orally, which were based on the most frequently occurring four-word chunks of language found in such series. The results indicate that frequent viewers have a significantly better knowledge of these items than occasional learners.

La recherche dans le domaine de l'apprentissage informel de l'anglais en ligne a mis en évidence le fait que ce phénomène est courant chez les apprenants d'anglais du secteur Lansad dans les universités françaises. La langue à laquelle ces apprenants sont exposés lors de visionnages de séries télévisées en version originale par le biais du streaming ou du téléchargement a aussi été caractérisée et quantifiée. Dans la présente étude, des apprenants ont d'abord répondu à un questionnaire pour déterminer la fréquence à laquelle ils visionnent de tels contenus. Ils ont ensuite participé à un test dans lequel ils se sont servis d'une échelle de connaissance de vocabulaire pour indiquer leur degré de connaissance d'une série de phrases incorporant les blocs de quatre mots les plus fréquents dans les dialogues de ces séries. Les résultats indiquent un écart significatif dans les scores à ce test entre ceux qui visionnent fréquemment ces séries, et ceux qui ne les visionnent qu'occasionnellement.

\section{INDEX}

Mots-clés: acquisition des langues, apprentissage informel, échelle de connaissance de vocabulaire, système complexe, visionnage de séries télévisées

Keywords: complex system, language acquisition, television series viewing, vocabulary knowledge scale

\section{AUTHORS}

\section{MERYL KUSYK}

Meryl Kusyk teaches English at the University Institute of Technology (IUT) Robert Schuman of the University of Strasbourg. She is currently studying the online informal learning of English in a joint PhD programme between the University of Strasbourg and the University of Karlsruhe. meryl.kusyk@unistra.fr

\section{GEOFFREY SOCKETT}

Geoffrey Sockett is a Senior Lecturer in language education at the University of Strasbourg and a member of the LiLPa research group. His areas of research include psycholinguistics, actionbased approaches and ICT. He has published a number of articles on informal learning in both French and English.gsockett@unistra.fr 